\title{
Every Thirty-six Hours
}

National Cancer Institute

\section{Source}

National Cancer Institute. Every Thirty-six Hours. NCI Thesaurus. Code C89791.

To be done at regular intervals ofevery 36 hours. 